\title{
Article
}

\section{Positive signs - How sign language typology benefits deaf communities and linguistic theory}

Pfau, R and Zeshan, Ulrike

Available at https://clok.uclan.ac.uk/16773/

Pfau, $R$ and Zeshan, Ulrike orcid iconORCID: 0000-0002-8438-3701 (2016)

Positive signs - How sign language typology benefits deaf communities and linguistic theory. Linguistic Typology, 20 (3). pp. 547-559. ISSN 1430-0532

It is advisable to refer to the publisher's version if you intend to cite from the work. http://dx.doi.org/10.1515/lingty-2016-0026,

For more information about UCLan's research in this area go to http://www.uclan.ac.uk/researchgroups/ and search for <name of research Group>.

For information about Research generally at UCLan please go to http://www.uclan.ac.uk/research/

All outputs in CLoK are protected by Intellectual Property Rights law, including Copyright law. Copyright, IPR and Moral Rights for the works on this site are retained by the individual authors and/or other copyright owners. Terms and conditions for use of this material are defined in the policies page.

\section{CLoK}

Central Lancashire online Knowledge www.clok.uclan.ac.uk 


\section{Positive signs - How sign language typology benefits deaf communities and linguistic theory}

Roland Pfau \& Ulrike Zeshan

(University of Amsterdam \& University of Central Lancashire)

\section{Introduction}

Sign language typology is the systematic comparative study of linguistic structures across sign languages, and has emerged as a separate linguistic sub-discipline over the past 15 years. It is situated at the crossroads between linguistic typology and sign language linguistics, the latter itself a relatively young discipline with its roots in the 1960s and 70s (McBurney 2001).

The first publications in sign language typology reported on large-scale comparative studies of grammatical/semantic domains, including negatives, interrogatives (Zeshan 2004a, 2004b, 2006), possession, and existence (Zeshan \& Perniss 2008). In sign language typology, a typical large-scale study comprises around three dozen sign languages and takes around five years. This is due to the fact that typologically usable sources such as reference grammars are not readily available for sign languages, and therefore, the majority of data are generated for the first time through the typological project itself.

Subsequent work has lessened the bias on European and other Western sign languages, as sign languages in other parts of the world are increasingly being documented. For instance, Zeshan et al. (2013) on numerals focus on typologically significant data from sign languages which have emerged in small-scale rural communities in the Global South. The importance of these rural sign languages for typological work is discussed in De Vos \& Pfau (2015).

The cross-fertilisation initiated by the advent of sign language typology is obvious: Typologists gain an entirely new dimension in their study of linguistic diversity, and sign language linguists gain a rich tool box of concepts and methods for discovering typological patterns across sign languages. Beyond theory and methodology, the impact that sign language typology research has on the deaf communities who are the primary users of these languages is discussed in Section 2. Section 3 discusses some areas in which sign language typology has made unique contributions to linguistic theory and has prompted discussions that may otherwise not have come to the surface.

\section{Sign language typology and deaf communities}

\subsection{Deaf communities: between oppression and recognition}

The relationship between sign language linguists and deaf communities has gone through a particular development because arguably, this relationship is qualitatively different from spoken language research. Although spoken language linguists, particularly those working in disadvantaged communities, may also engage in community action that is directly linked to their research, there is a 
different order of magnitude for sign languages because addressing linguistic issues is the single most important problem in deaf communities. This is true both historically and at present.

The historical oppression of deaf communities has largely taken the form of linguistic oppression and discrimination, with the hearing majority failing to recognise that sign languages are complete and complex linguistic systems. Consequently, deaf children were often, and sometimes still are, consciously deprived of access to sign languages, since spoken language was regarded as the only form of human language. Moreover, deafness was regarded as primarily a medical problem that needed to be treated and prevented. The change from this medical paradigm to a new paradigm, where deaf communities are regarded as linguistic and cultural minorities, and sign languages are recognised as linguistically on a par with spoken languages in all respects, was made possible by sign language linguists. This change of perspective has had important practical results, such as the legal recognition of sign languages in many countries, provisions for sign language interpreting, and bilingual approaches to deaf education that include the use of a sign language. Consequently, the community of sign language linguists has tended to take such issues very seriously, even if they have not always been discussed in explicit terms. The aim of this section is to discuss the specific contribution and impact of sign language typology in this context.

Today, many deaf communities have come a long way in terms of the recognition of sign languages. The education of deaf children, however, remains a challenge, and new medical advances, in particular the Cochlear Implant, have begun to threaten the viability of some deaf communities in the future. In addition, deaf communities themselves are now much more aware of research processes and results, and this has led to a new round of debates around the principles of sign language research, with key phrases such as "language ownership" and "deaf-led research". Sign language typology emerged in this intellectual climate.

\subsection{International networking}

A unique strength in typological work is the fact that people must work together across languages. Therefore, international networking has been a natural by-product of sign language typology. Given that (a) sign linguistics is still only just emerging in many countries and (b) the majority of countries where sign linguistics is established have a very limited number of academics involved in this field, international cooperation can have particularly powerful effects.

Across various linguistic disciplines, explicit direct comparison between signed and spoken languages has become increasingly prominent in recent years. The "h2m" ("hand to mouth") conference in Zurich in 2013, for instance, featured paired presentations on specific topics, including typology, by a sign language linguist and a spoken language linguist, with a summarising dialogue by both presenters at the end of each session. The EU Mercator network hosted a conference in 2015 on multilingualism and linguistic diversity, with a strong contingent of sign language presentations.

Within the wider context of such events, and their resulting publications, a conference series originated from sign language typology. The conference series began as a workshop called Crosslinguistic Sign Language Research (CLSLR) in 2006 at the Max Planck Institute for Psycholinguistics in Nijmegen, which at the time hosted the first sign language typology research group. As the members of this group were mostly deaf academics, this conference series developed in a way that was strongly 
influenced by the agendas and preferences of deaf participants. CLSLR was repeated in Nijmegen in 2007 and in Preston, UK, in 2008, at the newly established International Institute for Sign Languages and Deaf Studies (iSLanDS). The series was then renamed SIGN, and subsequent SIGN conferences were hosted in India (SIGN4 and SIGN6), Turkey (SIGN5), and China (SIGN7) - with numbers of participants steadily increasing. The SIGN conference series has been explicitly global from the beginning, and this is important for capacity building given the low numbers of researchers, and particularly deaf researchers, in sign linguistics.

Over time, the SIGN conference series has developed a number of special properties. Presenters are required to present either in the host country's sign language or in International Sign. The conference is preceded by a full-day workshop on International Sign, which is designed to improve communication between participants. Around $80-90 \%$ of participants tend to be deaf academics, students, and/or community leaders. Non-signers are accommodated in a limited number of slots with voiceover interpreting, e.g. for evening keynotes.

These design features are intended to enable an international community of deaf academics and other sign language users to come together at a conference that they regard as their own and that is maximally adapted to their preferences and needs. The most important aspect is direct access to all parts of the programme through sign languages without the need for interpreting.

\subsection{Publishing}

As more and more deaf individuals succeed in becoming academically qualified and participating in all aspects of academic life, it is becoming increasingly important to encourage deaf authors. Publications lie at the heart of academic credibility, and therefore, facilitating publications by deaf authors is an important avenue for deaf communities to gain more control over sign language research. Several edited collections have referred explicitly to the number of participating deaf authors, for instance, Mathur \& Napoli (2011) and Zeshan \& Perniss (2008). Also, recently published encyclopaedias contain numerous contributions (co-)authored by deaf researchers (Jepsen et al. 2015; Gertz \& Boudreault 2016).

Due to the international networking that is inherent in sign language typology research, there is now a broader context for the involvement of deaf academics in all aspects of publishing, including from regions of the world where sign language linguistics is beginning to establish itself. In 2006, a dedicated Sign Language Typology (SLT) book series was established, initially by the Ishara Press (Vol. 1 and 2), and subsequently as a co-publication between De Gruyter Mouton and Ishara Press (Vol. 3 onwards). The SLT series supports deaf authors, in particular by means of additional editorial assistance for publishing in English. In total, volumes SLT1 to SLT8 include 20 contributions by deaf authors or co-authors. Deaf academics also appear in other roles, including as single author of a monograph (Palfreyman, forthcoming), volume (co)-editor, and members of the editorial board.

The Ishara Press has also published academic works in sign languages, which allows deaf sign language users to add to their record of publications, and makes these works more accessible for a non-English speaking audience of sign language users. Like the Deaf Studies Digital Journal (DSDJ), the Signed Publications Series also serves another purpose, namely to encourage and popularise an 
"academic style" of signing (e.g. Panda, forthcoming). A signed academic text is a new type of genre that needs to be made known more widely.

These publications achieve a number of important results and can create powerful synergies beyond merely putting out research into the public domain: academic credibility for new deaf authors, access to academic publications in sign languages, intensification of international networks through the production of edited collections, and capacity building among deaf academics with respect to the various roles within publishing.

\subsection{Capacity building}

Sign language typology is well placed to stimulate increasing research by deaf communities on their own sign languages, especially in countries where this is a new undertaking. Due to the comparative and collaborative nature of this research, capacity building via cross-fertilisation is a naturally arising opportunity. For example, for the sign language typology project on semantic fields (Zeshan \& Sagara 2015), all research materials were translated by the research team into International Sign. This enabled data collection for the project by contributors with no or limited literacy in English. It is also important to consider how regular academic activities, such as summer schools in typology, or mentoring partnerships among researchers in sign language typology, could further support capacity building in deaf communities.

Another recent coordinated effort that has great potential for capacity building is the creation of reference grammars for sign languages. After an EU-funded project that created a blueprint for sign language reference grammars, consisting of a detailed table of contents, a manual, and a glossary (Quer et al., forthcoming; see also: http://parles.upf.edu/en/content/cost-signgram), a current follow-on project is putting this blueprint into practice by producing a series of reference grammars (www.sign-hub.eu). Unlike for spoken language typology, sign language typology cannot yet rely on any systematic reference grammars that conform to typological conventions, and this type of resource is needed urgently for the whole field of sign linguistics. Clearly, a reference grammar is a unique resource for deaf communities aspiring to have their languages documented in a systematic way.

\section{Sign language typology and linguistic theory}

Time and time again, studies on sign language structure have demonstrated that, for the most part, the attested patterns as well as the observed variation align well with what has been described for spoken languages (Sandler \& Lillo-Martin 2006). That is, certain modality-specific characteristics notwithstanding (Meier 2012), established typological classifications are generally applicable to sign languages. When it comes to constituent order, for instance, those sign languages for which a basic order has been identified display either SOV or SVO order. Yet, the order of constituents appears rather variable and is often different (OSV) in locative clauses (Napoli \& Sutton-Spence 2014). As for relative clauses, the typological distinction between head-internal and head-external relative clauses has been confirmed for sign languages, with Italian Sign Language (LIS) featuring the former and German Sign Language (DGS) featuring the latter type (Pfau \& Steinbach 2016). Taken together, the 
cross-modal application of typological classifications to sign languages as well as the comparison of sign languages to each other (see e.g. Schuit 2013) has yielded significant results and has provided strong arguments in favour of their status as fully-fledged natural languages.

However, beyond such striking cross-modal similarities, studies on a significant number of sign languages from all continents have also revealed typologically marked patterns, thus at the same time challenging the existence of alleged universals and adding to our understanding of the variation attested in natural languages (see e.g. Aronoff et al. (2005a) on morphological universals). We address three grammatical phenomena in order to illustrate how the study of sign languages can inform linguistic theory: wh-questions, verb agreement, and word order within the noun phrase.

\subsection{Wh-questions: going the wrong way?}

Studies on wh-questions in a large number of typologically diverse spoken languages have revealed a clear pattern: if the wh-word does not remain in its base position (as e.g. in Japanese), then it is displaced to the beginning of the clause, or, in generative terms, it is moved leftwards. Wh-movement has thus been claimed to proceed leftward universally. However, things are strikingly different in sign languages (Zeshan 2004b; Cecchetto 2012). In basically all sign languages studied to date, clause-final placement of a wh-sign is at least one of the options made available by the grammar - even if this is not the base position of the wh-sign - and in some sign languages, this is actually the only option. Moreover, in many sign languages, wh-signs are commonly doubled, that is, the same wh-sign appears in clause-initial and clause-final position. Both patterns are illustrated by the LIS subject wh-questions in (1) (Geraci et al. 2015: 135, 140).

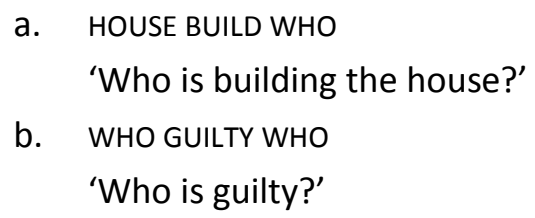

This state of affairs has sparked an interesting debate among sign linguists. Some scholars argue that based on these facts, the suggested universal cannot be maintained; rather, the sign language facts show that rightward movement is an option made available by Universal Grammar (Neidle et al. (1997) for American Sign Language (ASL); Cecchetto, Geraci \& Zucchi (2009) for LIS). In contrast, other researchers stick to the universal, be it by claiming that final wh-elements are not really wh-signs proper (e.g. Petronio \& Lillo-Martin (1997) for ASL), or by assuming that leftward movement of the wh-sign is followed by additional movement operations (e.g. Aboh, Pfau \& Zeshan (2005) for Indian Sign Language). ${ }^{1}$ Irrespective of the competing analyses, the phenomenon clearly illustrates that sign languages may provide novel data that are of significant typological value, as they may in turn inform typological investigations on spoken languages. In fact, the sign language patterns triggered a renewed search for comparable constructions in spoken languages (e.g. Aboh \& Pfau 2010). Still, even if clause-

\footnotetext{
${ }^{1}$ Note that the doubling cases are sometimes taken to exemplify a focus strategy (Petronio \& Lillo-Martin (1997) for ASL; Nunes \& de Quadros (2008) for ASL and Brazilian Sign Language).
} 
final placement of wh-elements turns out to be a typologically viable option, we still have to explain why sign languages favour this option while it appears to be rare across spoken languages (see Cecchetto et al. (2009) for an attempt).

\subsection{Agreement - or not?}

Another grammatical phenomenon that has received considerable attention in the sign linguistics literature are the so-called 'agreeing' or 'directional' verbs. Most of the sign languages studied to date feature verbs that can be modified to indicate their arguments. Leaving numerous complexities aside, the movement component of these verbs can be modified such that the beginning point of the movement coincides with the location associated with the subject while the end point coincides with the location associated with the object. In the DGS example in (2), the movement of the verb HELP thus starts at location 3 (front right), which has been established for the referent TEACHER by means of a pointing sign (INDEX) targeting that location, and moves towards location 1 in front of the signer's chest. The resulting meaning is 'he helped me', and consequently, the two loci are said to encode subject and object agreement, respectively (Padden 1988; Lillo-Martin \& Meier 2011).

\section{(2) YESTERDAY TEACHER INDEX ${ }_{3}{ }_{3} \mathrm{HELP}_{1}$ \\ 'Yesterday the teacher helped me.'}

It could thus be argued that in (2), features of a controller (the verbal arguments) are copied onto a target (the verb). But is this really an instantiation of agreement? In fact, the phenomenon displays typologically unusual properties which made some scholars challenge an account in terms of agreement. Here, we can only briefly address three important aspects. First, only a subset of verbs behaves like HELP in (2); actually, most verbs cannot be spatially modified in this way (the so-called 'plain' verbs; e.g. LOVE and UNDERSTAND in DGS). Crucially, across sign languages, group membership is determined by semantic (verb expresses concrete or abstract transfer) and phonological (verb is not body-anchored) factors (Meir 2002; Costello 2015). In contrast, typological evidence from spoken languages suggests that if a language has verbal agreement, it is marked across the board on all lexical verbs (Corbett 2006). ${ }^{2}$ Second, subject agreement appears to be more marked than object agreement: it is optional, and some verbs can only agree with their object - from a typological perspective, this is clearly an unusual state of affairs. ${ }^{3}$

Thirdly, except for the first person, the morpheme that spells out the agreement feature (i.e. the locus) does not have a fixed phonological form. Rather, its exact form is contextually determined. In (2), for instance, the relevant locus is introduced by the pointing sign. Some scholars have therefore suggested that sign languages only distinguish between first (locus close to signer) and non-first person (all other loci), thus contradicting the proposed universal that all languages distinguish between first, second, and third person (Ingram 1978).

\footnotetext{
${ }^{2}$ Auxiliaries may display exceptional behaviour, cf. English modal verbs.

${ }^{3}$ In Inuit Sign Language, directional verbs never agree with their subject; only the object locus is marked on these verbs (Schuit 2013).
} 
From the perspective of typology, the study of directional verbs had the positive effect of triggering efforts to search for comparable typological peculiarities in spoken languages - and with some success. It turns out (i) that there are languages in which only the Patient argument is marked on transitive verbs (Siewierska 2013), (ii) that languages exist which do not distinguish between second and third person - albeit in the pronominal system (Cysouw 2005), and (iii) that in some languages, agreement markers also display variable shape in that they copy phonological information of the controller ('literal alliterative agreement'; Aronoff, Meir \& Sandler 2005b). Taking these and other patterns into account, Costello (2015) offers a fine-grained typological comparison of agreement in spoken and signed languages, based on Corbett's (2006) criteria for canonical agreement. The study of verb agreement is thus a prime example of how sign language linguistics and linguistic typology can cross-fertilize each other.

\subsection{Word order within NP: issues of variation}

Only in recent years, corpora of considerable size of naturalistic sign language data have become available. Corpus data allow for testing generalizations that have previously been made based on elicited data and grammaticality judgments. In fact, the phenomena that we addressed in the previous sections have recently been investigated using corpus data (wh-questions for LIS; agreement for Australian Sign Language, British Sign Language, and Sign Language of the Netherlands), and in both cases, previous claims had to be reconsidered based on the patterns extracted from the corpora.

Of particular interest in the present context is the study by Mantovan (2015), which investigates the word order within the noun phrase in LIS from a typological and formal syntactic perspective. Previous studies on this topic suggested that $\mathrm{N}>\mathrm{Adj}>\mathrm{Num}>\mathrm{Dem}$ is the unmarked order within NP (i.e. that all modifiers follow the noun), as is illustrated in (3) (Bertone 2009, in Mantovan 2015: 90). However, data from the LIS corpus reveal (i) that Num>N>Adj>Dem is the most frequent order, (ii) that there is considerable variation in this domain, and (iii) that some of the variation can be explained by sociolinguistic factors, namely age and family background (Deaf family members).

\section{(3) BOOK NEW TWO INDEX dem \\ 'these two new books'}

From a typological perspective, it is noteworthy that all of the attested orders comply with Greenberg's Universal 20 (Greenberg 1963) and its recent extension and formalization in Cinque (2005). Still, while every single order aligns with previously established typological patterns, the amount of variation is striking. This raises the question whether a comparable degree of variation is observed in some spoken languages. Also, independent of the answer to this question, one should ask what causes this variation. Given the sociolinguistic factors that Mantovan identified, it seems likely that the specific acquisition situation as well as changing policies in Deaf education can be held 
responsible for at least some of the variation. Applying typological and sociolinguistic insights of this sort to (corpus-based) studies on variation in spoken languages is certainly a worthwhile endeavour. ${ }^{4}$

\section{Conclusion}

The preceding discussion clearly illustrates that sign language typology, a young and thriving research field, has had an important positive impact at both the community and the scientific level. Deaf communities benefit from sign language typology, as research in this domain fosters networking among and professionalization of deaf academics who, in turn, advance research in this field. When it comes to the linguistic study of natural language, sign languages also have a lot to contribute, as they add to our understanding of the possible variation among and within languages. Previous studies have shown that sign languages may both confirm and challenge typological claims and classifications based on spoken language data.

These positive achievements notwithstanding, much remains to be done. As far as typology is concerned, researchers should strive to include sign language data in their studies; at present, attempts in this direction are marginal. The World Atlas of Language Structures (http://wals.info/), for instance, contains two chapters on sign languages, but the other 142 chapters focus entirely on spoken languages. A noteworthy exception is the textbook on linguistic typology by Velupillai (2012), which features a comparative section on sign languages within every chapter. Also, Evans \& Levinson (2009) include sign languages in their critical discussion of language universals. More efforts of this type are necessary in order to raise awareness about the significant contributions that the linguistic study of sign languages can make.

Meanwhile, deaf communities are making parallel efforts to encourage sign language research in new contexts. A notable recent initiative has been the manual for sign language work within development cooperation (FAD \& WFD 2015). This publication is available both in English and in International Sign on video (www.slwmanual.info), and describes a deaf-led and community-based approach to sign language work in a development context. In many cases, such work will involve under- or undocumented sign languages, which is of immediate interest to sign language typology because of the potential for broadening our understanding of linguistic diversity across sign languages. It can be expected that there will be many beneficial effects if such initiatives can be brought to bear on the field of sign language typology.

\section{References}

Aboh, Enoch O. \& Roland Pfau. 2010. What's a wh-word got to do with it? In Paola Benincà \& Nicola Munaro (eds.), Mapping the left periphery: The cartography of syntactic structures, Vol. 5, 91-124. Oxford: Oxford University Press.

\footnotetext{
${ }^{4}$ Oomen \& Pfau (forthcoming) investigate clausal negation in Sign Language of the Netherlands based on corpus data, and they also observe interesting, yet systematic, variation. Moreover, they discuss the data from a typological perspective, comparing the patterns to those reported for other sign languages as well as to clausal negation in spoken languages.
} 
Aboh, Enoch O., Roland Pfau \& Ulrike Zeshan. 2005. When a wh-word is not a wh-word: The case of Indian Sign Language. In Tanmoy Bhattacharya (ed.), The Yearbook of South Asian languages and linguistics 2005, 11-43. Berlin: Mouton de Gruyter.

Aronoff, Mark, Irit Meir, Carol Padden \& Wendy Sandler. 2005a. Morphological universals and the sign language type. Yearbook of Morphology 2004. 19-39.

Aronoff, Mark, Irit Meir \& Wendy Sandler. 2005b. The paradox of sign language morphology. Language 81(2). 301-344.

Cecchetto, Carlo. 2012. Sentence types. In Roland Pfau, Markus Steinbach \& Bencie Woll (eds.), Sign language. An international handbook (HSK - Handbooks of Linguistics and Communication Science), 292-315. Berlin: De Gruyter Mouton.

Cecchetto, Carlo, Carlo Geraci \& Sandro Zucchi. 2009. Another way to mark syntactic dependencies: The case for right-peripheral specifiers in sign languages. Language 85(2). 278-320.

Cinque, Guglielmo. 2005. Deriving Greenberg's Universal 20 and its exceptions. Linguistic Inquiry 36. 315-332.

Corbett, Greville G. 2006. Agreement. Cambridge: Cambridge University Press.

Costello, Brendan D.N. 2015. Language and modality: Effects of the use of space in the agreement system of lengua de signos española (Spanish Sign Language). Amsterdam \& Vitoria: University of Amsterdam \& University of the Basque Country PhD dissertation. Utrecht: LOT.

Cysouw, Michael. 2005. What it means to be rare: The case of person marking. In Zygmund Frajzyngier \& David Rood (eds.), Linguistic diversity and language theories, 235-258. Amsterdam: John Benjamins.

Evans, Nicholas \& Stephen C. Levinson. 2009. The myth of language universals: Language diversity and its importance for cognitive science. Behavioral and Brain Sciences 32. 429-492.

Finnish Association of the Deaf (FAD) \& World Federation of the Deaf (WFD). 2015. Working together. Manual for sign language work within development cooperation. Helsinki: Finnish Association of the Deaf.

Geraci, Carlo, Robert Bayley, Anna Cardinaletti, Carlo Cecchetto \& Caterina Donati. 2015. Variation in Italian Sign Language (LIS): The case of wh-signs. Linguistics 53(1). 125-151.

Gertz, Genie \& Patrick Boudreault (eds.). 2016. The SAGE deaf studies encyclopedia (3 volumes). London: SAGE Publications.

Greenberg, Joseph H. 1963. Some universals of grammar with particular reference to the order of meaningful elements. In Joseph H. Greenberg (ed.), Universals of human language, 73-113. Cambridge, MA: MIT Press.

Ingram, David. 1978. Typology and universals of personal pronouns. In Joseph H. Greenberg (ed.), Universals of Human Language. Vol. 3: Word structure, 213-248. Stanford: Stanford University Press.

Jepsen, Julie B., Goedele De Clerck, Sam Lutalo-Kiingi \& William B. McGregor (eds.). 2015. Sign languages of the world. A comparative handbook. Berlin: De Gruyter Mouton.

Lillo-Martin, Diane \& Richard P. Meier. 2011. On the linguistic status of 'agreement' in sign languages. Theoretical Linguistics 37(3/4). 95-141.

Mantovan, Lara. 2015. Nominal modification in Italian Sign Language (LIS). Venice: Università Ca'Foscari PhD dissertation.

Mathur, Gaurav \& D onna Jo Napoli (eds.). 2011. Deaf around the world. The impact of language. Oxford: Oxford University Press.

McBurney, Susan. 2001. William Stokoe and the discipline of sign language linguistics. Historiographica Linguistica XXVIII:1/2. 143-186.

Meier, Richard P. 2012. Language and modality. In Roland Pfau, Markus Steinbach \& Bencie Woll (eds.), Sign language. An international handbook (HSK-Handbooks of Linguistics and Communication Science), 574601. Berlin: De Gruyter Mouton.

Meir, Irit. 2002. A cross-modality perspective on verb agreement. Natural Language \& Linguistic Theory 20. 413450. 
Napoli, Donna J. \& Rachel Sutton-Spence. 2014. Order of the major constituents in sign languages: implications for all language. Frontiers in Psychology 5. Article 376.

Neidle, Carol, Judy Kegl, Ben Bahan, Debra Aarons \& Dawn MacLaughlin. 1997. Rightward wh-movement in American Sign Language. In Dorothee Beerman, David Leblanc \& Henk van Riemsdijk (eds.), Rightward movement, 247-278. Amsterdam: John Benjamins.

Nunes, Jairo \& Ronice M. de Quadros. 2008. Phonetically realized traces in American Sign Language and Brazilian Sign Language. In Josep Quer (ed.), Signs of the time. Selected papers from TISLR 8, 177-190. Hamburg: Signum.

Oomen, Marloes \& Roland Pfau. Forthcoming. Signing NOT (or not): A typological perspective on standard negation in Sign Language of the Netherlands. To appear in Linguistic Typology.

Padden, Carol. 1988. Interaction of morphology and syntax in American Sign Language. New York: Garland.

Palfreyman, Nick. Forthcoming. Sign language varieties in Indonesia: a linguistic and sociolinguistic investigation. Berlin \& Lancaster: De Gruyter Mouton \& Ishara Press.

Panda, Sibaji. Forthcoming. MULTISIGN: Burundi Sign Language - Indian Sign Language Bilinguals. Ishara Signed Publications No.4. Lancaster: Ishara Press.

Petronio, Karen \& Diane Lillo-Martin. 1997. WH-movement and the position of Spec-CP: Evidence from American Sign Language. Language 73(1). 18-57.

Pfau, Roland \& Markus Steinbach. 2016. Complex sentences in sign languages: Modality - typology - discourse. In Roland Pfau, Markus Steinbach \& Annika Herrmann (eds.), A matter of complexity: Subordination in sign languages, 1-35. Berlin: De Gruyter Mouton.

Quer, Josep, Carlo Cecchetto, Caterina Donati, Carlo Geraci, Meltem Kelepir, Roland Pfau \& Markus Steinbach (scientific directors). Forthcoming. SignGram Blueprint: A guide to sign language grammar writing. Berlin: De Gruyter Mouton (open access online publication).

Sandler, Wendy \& Diane Lillo-Martin. 2006. Sign languages and linguistic universals. Cambridge: Cambridge University Press.

Schuit, Joke. 2013. Typological aspects of Inuit Sign Language. Amsterdam: University of Amsterdam PhD dissertation.

Siewierska, Anna. 2013. Verbal person marking. In Matthew S. Dryer \& Martin Haspelmath (eds.), The world atlas of language structures online. Leipzig: Max Planck Institute for Evolutionary Anthropology (Available online at http://wals.info/chapter/102; accessed on 28-08-2016).

Velupillai, Viveka. 2012. An introduction to linguistic typology. Amsterdam: John Benjamins.

Zeshan, Ulrike. 2004a. Hand, head, and face: Negative constructions in sign languages. Linguistic Typology 8. 158.

Zeshan, Ulrike. 2004b. Interrogative constructions in signed languages: Cross-linguistic perspectives. Language 80(1), 7-39.

Zeshan, Ulrike (ed.). 2006. Interrogative and negative constructions in sign languages. Nijmegen: Ishara Press.

Zeshan, Ulrike, Cesar Ernesto Escobedo Delgado, Hasan Dikyuva, Sibaji Panda \& Connie de Vos. 2013. Cardinal numerals in rural sign languages: Approaching cross-modal typology. Linguistic Typology 17. 357-396.

Zeshan, Ulrike \& Pamela Perniss (eds.). 2008. Possessive and existential constructions in sign languages. Nijmegen: Ishara Press.

Zeshan, Ulrike \& Keiko Sagara (eds.). 2016. Semantic fields in sign languages. Colour, kinship and quantification. Berlin \& Nijmegen: De Gruyter Mouton \& Ishara Press. 